\title{
Childhood Gastrointestinal Stromal Tumor
}

National Cancer Institute

\section{Source}

National Cancer Institute. Childhood Gastrointestinal Stromal Tumor. NCI Thesaurus.

Code C123906.

A gastrointestinal stromal tumor (GIST) occurring in childhood. Pediatric GISTs differ biologically from adult GISTs in that only $11 \%$ of pediatric GISTs have activating mutations of KIT and PDGFRA. 